\begin{tabular}{|c|c|}
\hline $\begin{array}{c}\text { Q IEEE } \\
\text { (19) }\end{array}$ & $\begin{array}{l}\text { IEEE Transactions on Geoscience } \\
\text { and Remote Sensing }\end{array}$ \\
\hline
\end{tabular}

\title{
Validation of SMOS L1C and L2 products and important parameters of the retrieval algorithm in the Skjern River Catchment, Western Denmark
}

\begin{tabular}{|r|l|}
\hline Journal: & Transactions on Geoscience and Remote Sensing \\
\hline Manuscript ID: & Draft \\
\hline Manuscript Type: & Regular paper \\
\hline Keywords: & Moisture, Soil, Microwave radiometry \\
\hline \multicolumn{2}{|l}{} \\
\hline
\end{tabular}




\title{
Validation of SMOS L1C and L2 products and important parameters of the retrieval algorithm
} in the Skjern River Catchment, Western

\section{Denmark}

\author{
Simone Bircher, Niels Skou, Fellow, IEEE and Yann Kerr, Senior Member, IEEE
}

\begin{abstract}
The Soil Moisture and Ocean Salinity (SMOS) satellite with a passive L-band radiometer is dedicated to surface soil moisture monitoring. In addition to soil moisture, vegetation optical thickness $\tau_{N A D}$ is retrieved (L2 product) from the acquired brightness temperatures (L1C product). The objective of this article is to present the validation work carried out in the Skjern River Catchment, Denmark. L1C/L2 data and the most sensitive parameters in the retrieval algorithm were analyzed by in situ data sets collected within one SMOS pixel (44 km diameter), including network and airborne campaign data. Consistent with worldwide findings, the retrieved soil moisture captures the precipitation dynamics well, but with too large amplitudes and a significant dry bias. The retrieved $\tau_{N A D}$ exhibits too high values and day-to-day variability. A filter based on L2 criteria removed RFI affected data and improved the $\boldsymbol{R}^{2}$ between retrieved and in situ soil moisture from 0.49 to 0.61 , while the bias remained (-0.092/-0.087 $\mathrm{m}^{3} / \mathrm{m}^{3}$, resp.). Likely error sources for the bias were located as (1) still present RFI, (2) potential link between low soil moisture and high $\tau_{N A D}$ and/or low roughness parameter $\left(\boldsymbol{H}_{\boldsymbol{R}}\right),(3) \sim 18 / 8 \%$ lower sand/higher clay fractions and $\sim 0.35 \mathrm{~g} / \mathrm{cm}^{\mathbf{3}}$ lower bulk density in SMOS algorithm than in situ, and (4) caveats in the Dobson dielectric mixing model. Substitution with the Mironov model and SMOS processor runs with site-specific input are planned. Differences in sampling depth between SMOS and in situ sensors (held responsible for too large SMOS amplitudes) and the role of organic surface layers will be investigated.
\end{abstract}

\section{Index Terms}

Passive microwaves, soil moisture, SMOS, L-band, L-MEB, validation.

S. Bircher and N. Skou are with the Department of Microwaves and Remote Sensing, DTU Space, Technical University of Denmark, 2800 Kgs. Lyngby, Denmark e-mail: subi@ space.dtu.dk.

Y. H. Kerr is with the Centre d'Etudes Spatiales de la Biosphère (CESBIO), 31401 Toulouse, France.

Manuscript received April 19, 2005; revised January 11, 2007. 


\section{INTRODUCTION}

Soilmoisture is one of the key variables in the water balance and thus, of high importance in a large range of applications from hydrologic, weather/climate modeling to water resources management or flood monitoring. Launched in November 2009 the Soil Moisture and Ocean Salinity satellite (SMOS) [1], [2] is the first space mission dedicated to global surface soil moisture $(\sim 0-5 \mathrm{~cm}$ depth) monitoring using the technique currently believed to be most effective [3], [4]. With a passive L-band (1.4 GHz) microwave radiometer on board SMOS has been acquiring data with global coverage every three days at a spatial resolution of $\sim 44 \mathrm{~km}$. From an initial soil moisture guess and other auxiliary input, soil moisture and vegetation optical thickness (L2 product) are retrieved for each node of a fixed grid (Discrete Global Grid, DGG) [5] with $\sim 15 \mathrm{~km}$ spacing, using multi-angular and full polarization information. The retrieval is done by a complex algorithm based on the inversion of the L-band Microwave Emission of the Biosphere (L-MEB) radiative transfer model [6] for an optimized fit with brightness temperatures $\left(T_{B}\right)$ acquired by SMOS (L1C product). At this point, an important step is SMOS Calibration/Validation (Cal/Val) across a range of climatic regions [7], which will steadily improve product quality.

Two complementary approaches have been widely used to attain the required data for SMOS validation: (1) shortterm airborne campaigns with intense ground sampling, e.g. [8]-[17], and (2) soil moisture networks, e.g. [12], [18]-[27]. Via the airborne measurements with a footprint of few kilometers the first method offers the advantage of stepwise validation across spatial scales, as well as direct comparison at brightness temperature level. The second method allows long-term monitoring at high temporal resolution. All of these features are relevant for the assessment of a parameter that is highly variable in both space and time and across scales [28]-[30].

One of the SMOS Cal/Val sites is situated in the Skjern River Catchment, Denmark. The northernmost intensely cultivated area in Europe features latitude-specific environmental conditions such as heathland and very sandy soils with large organic deposits, and is located at short distance to the coast line. With respect to satellite validation it benefits from temporally increased data acquisition at this latitude and pronounced flatness. In the framework of the Danish Hydrological Observatory and Exploratorium (HOBE) [31], the area of $\sim 44 \mathrm{~km}$ diameter around the selected SMOS DGG node 2002029 (refered to "SMOS pixel" hereafter) was equipped with a soil moisture and temperature network [32]. Additionally, an airborne campaign with the L-band radiometer EMIRAD-2 and concurrent ground measurements was carried out [33], [34].

Up to this point, SMOS validation results from several Cal/Val sites including the Danish site report a fairly consistent picture [32], [35]-[39]: SMOS initial/retrieved soil moisture overestimate/underestimate in situ soil moisture with biases in the order of $0.05-0.15 \mathrm{~m}^{3} / \mathrm{m}^{3}$ and $0.02-0.2 \mathrm{~m}^{3} / \mathrm{m}^{3}$, respectively. Meanwhile, temporal trends are well reproduced by the retrieved SMOS soil moisture ( $\mathrm{R} \sim 0.6-0.8)$ with a tendency of the latter to overestimate the dynamics (larger amplitudes). Only in West Africa constant overestimation by retrieved SMOS soil moisture was found [40], while low temporal correlation $(\mathrm{R}$ mostly $<0.5)$ was solely reported from Southern Germany [36]. Possible explanations for the observed deviations currently under discussion include (1) a mismatch between sampling depth of conventional soil moisture sensors $(\sim 5-7 \mathrm{~cm})$ and the L-band soil emission depth $(<$ 
$5 \mathrm{~cm}$ ), (2) effects due to the large disparity in spatial scale between SMOS and in situ measurements (e.g. biased in situ network averages), (3) inaccuracies in the retrieval algorithm and related input, (4) inacurracies in the in situ measurements, and (5) Radio Frequency Interferences (RFI) [41], [42]. Depending on prevailing environmental conditions and measurement setups, the respective contributions of these potential error sources must be variable for the different $\mathrm{Cal} / \mathrm{Val}$ sites.

So far, SMOS validation work has focused on SMOS L2 soil moisture and the L1C brightness temperature product [17], [34], [35], [43], [44]. However, to investigate uncertainties inherent in the SMOS retrieval algorithm, also the most sensitive input parameters should be checked. In this regard, only few studies seem to exist [37], [38]. The objective of this article is to present the comprehensive validation work carried out at the Danish validation site. This includes analysis of the SMOS L1C/L2 products as well as the most sensitive algorithm parameters by means of the network and airborne campaign data sets. Previous findings from [32], [34] are picked up, and together with results of more in-depth analysis put in context with the studies at other Cal/Val sites. Based upon this, most likely error sources for the current discrepancies at the Danish site are located.

\section{STUdy SITE/DATA}

\section{A. Location/environmental conditions}

The Skjern River Catchment is situated in Western Denmark and covers approximately $2500 \mathrm{~km}^{2}$ (Fig. 1). The climate is temperate-maritime with mean winter/summer temperatures of $\sim 2 / 16^{\circ} \mathrm{C}$, respectively, and an approximate annual precipitation of $800-900 \mathrm{~mm}$. The eastern margin of the catchment is situated at the rim of the ice sheet during the latest glacial advance with mainly loamy soils on undulating calcareous tills. The major part comprises the primal fluvioglacial outwash plain with very sandy soils and sediments (75-100\% sand), while poorly drained basins have been filled with organic material [45]. The natural soil type is podsol covered by a pronounced moss and raw humus layer $(\sim 5-20 \mathrm{~cm}$ thick). Nearly $80 \%$ of the land is under intensive cultivation, intermixed with patches of spruce forest $(\sim 10 \%)$, as well as heath/grassland $(\sim 6 \%)$. The area is sparsely populated. Within the catchment four HOBE study sites (Fig. 1b) [31] have been maintained to assess a wealth of hydrological parameters. The catchment is well-covered with climate and weather stations operated by the Danish Meteorological Institute (DMI). The daily precipitation data presented in this article are extracted from the DMI $10 \times 10 \mathrm{~km}$ precipitation grid nodes [46] contained within the SMOS pixel (Fig. 1). For each day the shelter correction factor of the corresponding month (category B) is applied [47]. The SMOS pixel around DGG node 2002029 (55.957 N, 9.131 E) was chosen for validation as it features minimal open water fraction while covering a substantial part of the catchment (Fig. $1 \mathrm{a}+\mathrm{b})[32]$.

\section{B. Soil moisture and temperature network}

A soil moisture and temperature network with 30 stations spatially distributed within SMOS pixel 2002029 was installed during fall 2009. To a priori enhance the likelihood of a representative large-scale network average for comparison with SMOS data, the individual stations were distributed according to the respective fractions of six 
so-called composite classes combining $82 \%$ of the prevailing land cover, top- and subsoil conditions [32]. Crop type frequency was also considered, and the network was aligned with the long-term mean annual north-east south-west precipitation gradient (Fig. 1b). Per station, soil moisture and temperature within the $0-5 \mathrm{~cm}, 20-25 \mathrm{~cm}$ and 50-55 cm depth ranges of the mineral soil, and in the organic layer in case of the sites with natural vegetation (forest and heath), are measured by means of ECH2O 5TE capacitance sensors ${ }^{1}$ and logged at 30 minute intervals. Soil moisture calibration checks for the $0-5 \mathrm{~cm}$ layer showed that sensor accuracy was within the declared $+/$ $0.03 \mathrm{~m}^{3} / \mathrm{m}^{3}$ range, which is in line with sensor accuracies of other large scale studies, e.g. [16], [48]. From soil samples taken at the $0-5 \mathrm{~cm}$ depth of each network station, percentages of sand, silt and clay were determined using standard procedures, and soil bulk densities calculated.

\section{Airborne campaign}

The HOBE airborne campaign [33], [34] took place in spring 2010. Four flights with the passive L-band microwave radiometer EMIRAD-2 [49] were carried out around SMOS ascending overpasses ( 06:30 a.m. local time) as shown in Fig. 1b. Simultaneously, ground measurements were taken within three $2 \times 2 \mathrm{~km}$ patches (agricultural land, heath/grassland and forest, Fig. 1c-e). The $-3 \mathrm{~dB}$ swath width was $\sim 1.4 \mathrm{~km}$ resulting in $\sim 35 / 75 \%$ coverage of the SMOS pixel/ground patches, respectively. Measurements were acquired at 0 and $40^{\circ}$ incidence angles and in full polarization mode. The EMIRAD data was calibrated, RFI-filtered and georeferenced to the ground using standard procedures [34].

Moisture of the mineral soil was measured with hand-held Delta T ML2x ThetaProbes ${ }^{1}(0-6 \mathrm{~cm}$ depth $)$ along several transects and at some locations gravimetric samples were taken. The data was recalculated using site-specific calibration curves. In case of heath and forest, readings/samples were also acquired from the moss/organic layers at the cost of less sampling points. Land cover information was recorded for each sampling point. At the beginning and towards the end of the campaign destructive vegetation sampling for vegetation water content (VWC) estimation was carried out on agricultural land and heath. Surface roughness transects were measured on a flat barley field as well as on a potato field with pronounced row structure (spanning the expected conditions) and standard deviations of the height, $S_{D}$ calculated. At the beginning the majority of agricultural fields were of bare appearance. During the campaign a significant increase in vegetation water content was observed within heath and agricultural land, along with an increase in overall roughness due to the ongoing plantatation of potatoes.

\section{SMOS}

The SMOS measurement and soil moisture retrieval concept is described in detail in [2], [5], [50]. The received radiation (proportional to $T_{B}$ ) used for the retrieval at each DGG node per SMOS overpass originates from the so-called working area $(\sim 123 \times 123 \mathrm{~km})$. It integrates observations ("snapshots") made at horizontal and vertical polarizations $(\mathrm{H}$ and $\mathrm{V})$ and a range of incidence angles $\left(\sim 0-60^{\circ}\right) /$ view directions, and is weighted by the shape

\footnotetext{
${ }^{1}$ Mention of manufacturers is for the convenience of the reader only and implies no endorsement on the part of the authors
} 
of the SMOS antenna pattern. Thus, $\sim 80-90 \%$ of the signal are emitted from the center area with a diameter of $\sim 44 \mathrm{~km}$.

The auxiliary parameters to initiate the algorithm are provided on a $4 \times 4 \mathrm{~km}$ grid (Discrete Flexible Fine Grid, DFFG) spanning the working area of each DGG node. They include land cover information (ECOCLIMAP), soil property data (\% sand and clay from the FAO data set, soil bulk density from the Global Gridded Surfaces of Selected Soil Characteristics for International Satellite Land Surface Climatology Project, ISLSCP), Leaf Area Index (LAI from the MODerate Resolution Imaging Spectroradiometer, MODIS), as well as the first soil moisture guess, temperature and other climate parameters (European Centre for Medium-range Weather Forecasting, ECMWF, products) [51]. The SMOS L2 processor uses different forward model versions with specific parameters for different land covers to account for mixed land cover pixels at large spatial scales. The ECOCLIMAP database is grouped into few generic classes. Non-permanent land cover classes (e.g. frost and snow) are successively updated based on the ECMWF product. Radiometric land cover fractions (referred to "FMO fractions" hereafter) are estimated for the working area by means of the antenna weighting pattern. The class with the highest radiometric fraction determines the choice of the forward model and auxiliary input, while the other classes contribute with fixed default values.

L-MEB is based on the relationship between $T_{B}$, physical temperature $\mathrm{T}$ and emissivity e/reflectivity $\mathrm{r}$, which in turn is related to the soil's dielectric constant after segregating atmosphere, vegetation and surface roughness contributions 2. Taking advantage of the large contrast between the dielectric properties of water and solid soil particles at L-band, soil moisture is linked to the dielectric constant via the Dobson dielectric mixing model [52], [53]. The replacement with the Mironov model [54] is currently under discussion. While Dobson is empiricallyderived from data sets with sand fractions $<50 \%$, Mironov is physically-based and built upon data sets spanning the entire soil type range up to pure quartz sand. Dobson requires soil moisture and temperature, clay and sand \%, dry soil bulk density and solid particle density as input, Mironov only uses the first three. Atmospheric attenuation of L-band emissions is generally low. Several parameters are used in L-MEB to describe the vegetation transmissivity, namely the single scattering albedo of the canopy $(\omega)$, vegetation optical depth at nadir $\left(\tau_{N A D}\right)$ and its incidence angle correction for non-nadir views at both polarizations $\left(t t_{H} / t t_{V}\right)$. The correction of surface roughness is done by parameters representing the intensity of the effects $\left(H_{R}\right)$, polarization mixing effects $\left(Q_{R}\right)$, and modulation of the reflectivity as a function of the incidence angle for both polarizations $\left(N_{R H} / N_{R V}\right)$. In addition to soil moisture, the soil characteristics (temperature, texture and bulk density) and the choice of $\tau_{N A D}$ and $H_{R}$ have most impact on the modeled $T_{B} \mathrm{~s}$ (highlighted in red in Fig. 2), e.g. [55]-[58].

\section{PRevious SMOS VALIDATION RESUlts}

\section{A. Soil moisture and temperature network [32]}

A first comparison between the 0-5 cm network averages and the SMOS soil moisture (L2) product over the year 2010 showed comparable trends with $R^{2}$ of $0.49 / 0.67$ for SMOS retrieved/initial soil moisture. The corresponding RMSE and biases (average residuals from expected value) are $0.102 / 0.061 \mathrm{~m}^{3} / \mathrm{m}^{3}$ and $-0.092 / 0.057 \mathrm{~m}^{3} / \mathrm{m}^{3}$, indicating significant under-/overestimation of the network data. The precipitation seemed well reflected over time 
in both network and SMOS soil moisture, but with larger amplitudes in case of the retrieved L2 product. The agreement between the $0-5 \mathrm{~cm}$ network temperature average and the initial SMOS surface temperature is very good with RMSE, bias and $R^{2}$ of $1.1{ }^{\circ} \mathrm{C},-0.2{ }^{\circ} \mathrm{C}$ and 0.97 , which is in accordance with findings from [37]. Likewise, we assume that no uncertainty is introduced in the retrieval algorithm by this parameter. The comparison of the dielectric constant's real part (direct sensor output) network average and the SMOS dielectric constant's real part derived from a non cardioid model revealed RMSE, bias and $R^{2}$ of $3.95 \mathrm{~F} / \mathrm{m},-2.30 \mathrm{~F} / \mathrm{m}$ and 0.49 . As the SMOS dielectric constant is computed from retrieved soil moisture using the Dobson model, an $R^{2}$ s equal to the one of the soil moisture comparison implies that at both comparison levels the uncertainty is consistent and remains either on the network or the SMOS data side.

\section{B. Airborne campaign [33], [34]}

Constantly small rain events occurred before and during the campaign, leading to low temporal soil moisture variability, while the spatial variability was generally high. In agreement with data recordings in Northern Germany [43] driest conditions were found in the mineral soils of the agriculture patch. Highest moisture contents were clearly found in the organic layers in the heath and forest patches, implying that with maximum likelihood L-band emissions originate from this substrate [33].

From the mineral soil moisture data $T_{B}$ s were point-wise estimated by means of L-MEB using land-cover specific settings, and patch-wise averaged for comparison with EMIRAD. [34]. The uncertainty in the modeled $T_{B}$ s turned out to be very high $(5-20 \mathrm{~K})$ when the most sensitive model parameters were varied within most likely value ranges. However, for each land cover class a combination of parameters could be selected to bring modeled and EMIRAD data in good agreement. Replacing Dobson with the Mironov model decreased the overall RMSE from 11.5 K to $3.8 \mathrm{~K}$, which is plausible given the high sand contents in the Skjern River Catchment. RMSEs were largest in case of agricultural land, which is consistent with results of [43]. They explain it with higher variability within the intensely cultivated area. However, we found the spatial variability in agriculture to be significantly smaller than in forest and heath. We rather attribute the good fit in the two latter to parameter tuning. Considering only the mineral soils, resulted in compensation of the $\tau_{N A D}$ and $H_{R}$ parameters for the neglected wet organic substrate (lower values within the uncertainty range compared to agriculture). Still, the chosen $H_{R}$ s for all land covers were significantly higher than the SMOS default, which is concordant with literature findings, e.g. [57], [59], [60]. Using an $N_{R H} / N_{R V}$ combination of $0 /-1$ instead of the SMOS default $2 / 0$ further increased the agreement.

EMIRAD data averaged at SMOS scale and corresponding SMOS $T_{B}$ s were also in the same range with a positive offset of the airborne data (mean RMSE=9.7 K). However, strong RFI limited this comparison to one day (May 2). The bias clearly increased when comparing the mean modeled patch $T_{B}$ s averaged over the SMOS pixel using the respective FMO fractions as weights (average RMSE of $15.9 \mathrm{~K}$ ). This issue will be resumed in Section V. Neither using the EMIRAD antenna pattern to weight the average of the modeled $T_{B}$ s nor the SMOS antenna pattern to estimate a weighted mean of EMIRAD data over the SMOS pixel did improve the results over simple averaging. 


\section{Methods}

\section{A. SMOS data preparation}

All SMOS data used in this work stems from consistent data sets reprocessed by means of the state of the art L1/L2 prototype algorithm (V3.46/V4.00) in case of the L1C/L2 products, respectively. L1C data was transferred from antenna to Top Of Atmosphere (TOA) level (XY to HV) by applying Faraday and geometric rotations. L1C and L2 data were filtered using two criteria from the L2 product [51]: (1) absolute abscissa of dwell line ( $X \_S W A T H$ ) $<10000$ (corresponding to $\sim 320 \mathrm{~km}$ out of max. $1000 \mathrm{~km}$ swath width), (2) probability that no anomaly occurred about the fit $\left(C H I 2 \_P\right)>0.5$. If the X_SWATH is too large, only a limited number of snapshots were available for the retrieval. There could also be image reconstruction issues at the edge of the swath [37]. A high enough CHI2_P makes sure that retrievals where the modeled and measured $T_{B}$ s fully disagree (e.g. RFI) or fit too well (only few snapshots) are discarded. Two additional criteria previously applied in [34] turned out redundant. In case of the L1C data only one month around the airborne campaign was used. Filtered $T_{B} \mathrm{~s}$ were further cut off at $300 \mathrm{~K}$. After filtering the L2 product of DGG node 2002029 for the entire year $201041 \%$ of the data, from ascending (morning) overpasses only, was left. At the U.S. validation sites [37], [39] both reported less good validation performance of the descending (evening) overpasses. A clear advantage of the ascending overpasses is the nearly thermal equilibrium state between atmosphere, vegetation and ground in the early morning, which favors the retrieval. [37] further suggested a disturbing impact of convective rainfall during the times of the descending overpasses at the studied watersheds. However, at the Danish site we assign the majority of the filtered data to RFI contamination. For a test period (April - June 2010) our filtering was checked against an RFI detection scheme based on SMOS level 1A data developed by [61]. This pointed to the same overpasses being affected by RFI when using the number of snapshots affected by RFI $<35 \%$ and the total number of available snapshots $>140$ as thresholds.

\section{B. Further SMOS data validation}

1) Refined soil moisture comparison: For each SMOS overpass (filtered data) during the year 2010, the two nearest half-hourly network measurements were extracted and averaged. This data was compared with the initial and retrieved SMOS soil moisture, and put in relation with the original network - retrieved SMOS soil moisture comparison using unfiltered data [32]. To check whether certain subgroups could possibly better explain the SMOS data than the entire network, the comparison was also performed with the network data set grouped into (1) soil type classes after [45] according to the estimated network texture data, (2) land cover classes as recorded at each station, and (3) composite classes (jointed land cover and soil type information) as used to place the network stations, see II-B and [32]. Specifications about these subgroups are given in Table I. It was also investigated whether the agreement was depending on seasons by grouping the data accordingly (winter: January-February and December, spring: March-May, summer: June-August, autumn: September-November).

2) Refined brightness temperature comparison: An attempt was made to model brightness temperatures from the soil moisture data of the mineral soil of each network station during a month centered on the campaign window 
(April 18 - May 18, 2010). The modeled network $T_{B} \mathrm{~s}$ at $40^{\circ}$ incidence angle were averaged over all stations for $\mathrm{H}$ and $\mathrm{V}$, respectively, and compared to the corresponding SMOS L1C data (average between 35 and $45^{\circ}$ incidence angles), the EMIRAD $T_{B} \mathrm{~s}$ as well as the modeled campaign in situ data. With respect to the last, the mean modeled patch $T_{B}$ s were averaged over the SMOS pixel using the respective FMO fractions as weights (bare soil and low vegetation "'FNO"' with 90/10\% for agriculture and heath, respectively., and forest "'FFO"' fractions: $77 \%$ agriculture, $8 \%$ heath and $15 \%$ forest, referred to "'weighted model patch averages"' hereafter).

Taking advantage of the findings from the analysis on the solid airborne campaign data sets of high spatial coverage, the L-MEB settings were adopted from [34]. Thus, parameters not mentioned in the following are set to values congruent with the one of the previous study. The Mironov dielectric mixing model was applied and $N_{R H} / N_{R V}$ set to $0 /-1$, respectively. Soil temperatures were extracted from the respective network station measurements and the clay percentages estimated from the respective network texture data.

In case of $H_{R}$ constant values were chosen for the entire month. For heath and forest classes 1.1 and 1.0 were applied while in case of the agriculture classes distinction was made between flat conditions (spring/winter cereal and grass) and rough conditions (bare potato fields) with assigned values of 0.58 and 1.17 , respectively. The soil moisture-dependent parameterization of $H_{R}$ was neglected (i.e. $H_{R}=H_{R_{-} M i n}$ ) as it remains controversial [62].

A constant $\tau_{N A D}$ of 0.2 was chosen for the entire month in case of coniferous forest. For the heath and agricultural land classes $\tau_{N A D}$ was derived from the vegetation water content estimations during the campaign. As there was a significant increase in VWC, it was interpolated between the two sampling dates (April 28 and May 06) and extrapolated to span the entire month. The only exception was agriculture grass where only one measurement was available per sampling day so that an average value of 0.274 was constantly used. From these monthly VWC data sets $\tau_{N A D}$ values were calculated using the linear relationship developed by [63]: $\tau_{N A D}=\mathrm{b} \cdot$ VWC, where $\mathrm{b}$ is a vegetation parameter, amongst others dependent on canopy type/structure. $b$ was defined per land cover class based on literature: 0.15 for cereal and 0.3 for agriculture grass (e.g. [63]), and 0.12 for scotch heather and natural grass (e.g. [64]). This resulted in $\tau_{N A D}$ values (April 28/May06) of 0.039/0.073 for natural grass, $0.058 / 0.083$ for scotchheather, 0.002/0.021 for spring cereal, and 0.090/0.185 for winter cereal, respectively. Due to the extrapolation at the beginning of the time span some of the values were negative and thus, adjusted to 0 . This is reasonable as the fields were just prepared and sown in this period. The comparably low values in case of forest and heath classes result from the compensation for the not considered organic layers, see III-B and [34].

3) Comparison of initial/retrieved SMOS $\tau_{N A D}$ with in situ modeling $\tau_{N A D}$ : The SMOS initial $\tau_{N A D}$ is originally obtained from the MODIS LAI data product.

For each retrieval the SMOS initial $\tau_{N A D}$ is either updated with the retrieved value of the previous overpass if its reliability is high enough according to the Data Quality Index (DQX, retrieved standard deviation), or anew derived from the MODIS LAI data product, where it first originates from. For comparison with the SMOS initial and retrieved $\tau_{N A D}$ the in situ $\tau_{N A D}$ values used for the modeling of each campaign sampling point were aggregated over the respective patches (agriculture, forest and heath). The average was weighted by the fractions of the respective land cover classes within each patch (noted for each point during the sampling). As these fractions were 
temporally variable for the agriculture patch, they were again estimated for each day by interpolating/extrapolating between/around the campaign days, and where negative adjusted to 0 . We are aware of the fact that such an averaging might not correspond to the full truth as the vegetation optical depth exhibits nonlinear effects over scales. However, we believe it still gives an impression of the expected order of magnitude of this parameter at larger scales.

4) Comparison of SMOS soil properties (FAO/ISLSCP) with in situ samples: The SMOS FAO soil texture (\% clay and sand) and ISLSCP soil bulk density of DGG node 2002029 at $4 \mathrm{~km}$ grid spacing were aggregated by computing (1) simple averages (geometric mean) for the working area and the SMOS pixel, and (2) a weighted average for the working area by means of the SMOS antenna weighting pattern (radiometric mean). For comparison the corresponding in situ soil property data $(0-5 \mathrm{~cm}$ depth) was aggregated (1) by averaging the respective values from the individual network samples, and (2) by averaging the respective values from all campaign samples within each sampling patch (agriculture, forest and heath). Again, these three patch means were averaged over the SMOS pixel using the FMO fractions as weights (see Section IV-B2).

5) Comparison of SMOS FMO land cover fractions (ECOCLIMAP) with CORINE Land Cover 2000: Finally, land cover fractions of the CORINE Land Cover Classification 2000 [65] at $100 \mathrm{~m}$ grid spacing were averaged over both the working area as well as the SMOS pixel (geometric mean) of DGG node 2002029. These averages were then compared with the correpsonding SMOS FMO fractions (ECOCLIMAP) at $4 \mathrm{~km}$ grid spacing (radiometric mean over working area).

\section{RESULTS AND DISCUSSION}

\section{A. Refined soil moisture comparison}

Fig. 3 displays the comparison of the $0-5 \mathrm{~cm}$ network soil moisture average over all 30 stations with the initial and filtered retrieved SMOS soil moisture data for the year 2010. The corresponding average mean of daily precipitation of the DMI $10 \mathrm{~km}$ grid nodes contained within SMOS pixel 2002029 as well as the FMO fractions are plotted along. The last one show that no retrieval was performed when the soil was frozen or snow covered. Precipitation seems to be well reflected by both SMOS and in situ data and we can see a clear trend between the soil moisture data sets. Still, the dynamic of the retrieved SMOS data is stronger and the significant overestimation/underestimation of SMOS initial/retrieved soil moisture compared to the network data clearly visible. RMSEs, biases and $R^{2}$ s between network and SMOS are 0.061/0.094 $\mathrm{m}^{3} / \mathrm{m}^{3}, 0.057 /-0.087 \mathrm{~m}^{3} / \mathrm{m}^{3}$ and $0.67 / 0.61$ for initial/retrieved SMOS soil moisture, respectively.

Fig. 4 depicts a scatter plot of the $0-5 \mathrm{~cm}$ soil moisture network average and the filtered as well as the unfiltered retrieved SMOS data for the entire year 2010. The corresponding statistics (Table I) demonstrate a clear improvement in the $R^{2}$ from 0.49 to 0.61 and a slight decrease in the RMSE/bias from $0.102 /-0.092$ to $0.094 /-0.087 \mathrm{~m}^{3} / \mathrm{m}^{3}$ for the unfiltered/filtered SMOS data, respectively. Likewise, the statistics of the dielectric constant's real part comparison improved when using the filtered SMOS data from the non Cardioid model with RMSE, bias and $R^{2}$ of $3.5 \mathrm{~F} / \mathrm{m}$, $-2.5 \mathrm{~F} / \mathrm{m}$ and 0.62 (not shown). 
Fig. 5 shows the comparison of the filtered retrieved SMOS data with $0-5 \mathrm{~cm}$ soil moisture network data grouped into (a) soil types, (b) land cover classes, (c) composite classes, and (d) four seasons. The statistics (Table I) indicate that overall only the sand class and the summer period by itself achieve as good statistical results as the entire network average. It is not surprising that the sand class behaves very similarly as it includes $80 \%$ of the stations. Furthermore, a slightly smaller bias for the comparably dry sand stations only is logic given the SMOS dry bias. The better agreement over the summer months is in line with [35] who reported a more pronounced bias in winter compared to the summer at the Australian SMOS Cal/Val site. The fact that none of the subgroups performs significantly better enhances our confidence in the representativeness of the chosen network setup.

\section{B. Refined brightness temperature comparison}

Fig. 6 shows surface soil moisture measured by the network, by means of the campaign readings and filtered initial/retrieved SMOS data, the mean of daily precipitation of the DMI $10 \mathrm{~km}$ grid nodes contained within SMOS pixel 2002029, and corresponding brightness temperatures at $40^{\circ}$ incidence angle and for $\mathrm{H}$ and $\mathrm{V}$ polarizations, respectively, for a month centered at the airborne campaign (April 18 - May 18, 2010). In terms of brightness temperatures filtered SMOS L1C data is depicted together with the EMIRAD data, weighted model patch averages of the campaign data, and the modeled network average. The soil moisture network data includes the $0-5 \mathrm{~cm}$ average over all stations as well as data of one station within each campaign sampling patch (agriculture, heath and forest). In case of the campaign data the three patch means and their weighted average over the SMOS pixel using the FMO fractions are shown.

The figure assembles previous findings and shows that the pattern prevails throughout the added data from the one month period. The weighted model patch averages are constantly drier than the network averages as the campaign sampling patches only exhibit very sandy soils with comparably dry conditions, while the network also observes the "'wetter"' more clayey soils. Likewise, the more pronounced SMOS L1C data $T_{B}$ overestimation by the weighted model patch average compared to the one by EMIRAD is probably attributable to these scale effects. In contrast, the average modeled network $T_{B} \mathrm{~s}$ show a consistent underestimation of the SMOS $T_{B} \mathrm{~s}$, which would actually be expected to explain the higher network soil moisture values compared to the ones retrieved by SMOS. Indeed, several studies report a warm bias of SMOS $T_{B}$ s compared to tower-based and airborne radiometer measurements as well as modeled in situ data [17], [35], [43]. However, for short time periods the opposite trend with lower SMOS $T_{B}$ s was also discovered in the studies of [17] and [43]. As we only have few campaign sampling days to compare with, it is thus likely that a differing pattern could persist over longer timeframes. The difference in modeled average network and campaign $T_{B}$ s seems too large to be solely explicable by the described scale effects. A major part is probably connected to the large uncertainties inherent in the $T_{B}$ modeling [34], [43], which can be especially pronounced at small spatial scales [44]. In the network data modeling uncertainties are clearly enhanced compared to the campaign data modeling as we have less direct observations for each station/day (e.g. information on land cover and surface conditions). Due to persistent low rainfall variability during the observation period it is difficult to make statements about the temporal dynamics in the data. However, the modeled network data is clearly 
not able to capture the two more significant rain events towards the end of the studied time window, while they are well-reflected in the respective soil moisture data. A further comparison between modeled $T_{B} \mathrm{~s}$ of individual overflown network stations with corresponding EMIRAD data also pointed to quite large deviations between the two, especially in case of stations within cereal fields and less sandy soils (not shown). But the reliability of such a comparison of two measurements integrating over very different spatial scales is again questionable.

\section{Comparison of initial/retrieved SMOS $\tau_{N A D}$ with in situ modeling $\tau_{N A D}$}

The lowest panel in Fig. 6 shows the initial and filtered retrieved SMOS $\tau_{N A D}$ and the corresponding $\tau_{N A D}$ values on average used for the in situ modeling within the agriculture, heath and forest patches, respectively.

The SMOS initial $\tau_{N A D}$ follows the mean agriculture $\tau_{N A D}$, especially between the two vegetation sampling days, with a likewise increasing trend. During the entire month, the S_TREE_1 parameter in the SMOS L2 product was set to 12, meaning that retrieval based on the FNO settings (low vegetation) was triggered. This is in accordance with the FMO fractions depicted in Fig. 3. Thus, the applied initial $\tau_{N A D}$ seems to be in the right order of magnitude. The retrieved SMOS $\tau_{N A D}$ values lie in considerably higher range which is meaningful as the retrieved value should now also account for the forest contribution (high vegetation opacity). However, as they are actually in the order of the mean forest $\tau_{N A D}$, we assume them to be too high. Also, the data is very noisy, though an increasing tendency is visible.

The observation period is too short for a final statement on the behavior of the vegetation optical depth. However, our findings are in good agreement with the ones of [37] who studied longer time frames at some watersheds in the U.S. They suspect the large day to day variability (not relatable to changes in vegetation) to be associated with the shift between using the updated retrieved $\tau_{N A D}$ value of the previous overpass and the estimates from the MODIS LAI data as model input. They also report a positive bias as well as a lack of seasonal response and point out that at this stage the retrieved parameter is not a reliable indicator of VWC. Similarly, [38] reported for other U.S. validation sites that the retrieved SMOS $\tau_{N A D}$ did not exhibit a clear correlation with the MODIS LAI.

\section{Comparison of SMOS soil properties (FAO/ISLSCP) with in situ samples}

Table II lists the average fractions (geometric mean of working area and SMOS pixel and radiometric mean for the former) of the SMOS FAO/ISLSCP soil properties for DGG node 2002029 as well as the network and campaign 0-5 cm sample averages derived for the corresponding SMOS pixel. As expected, the percentages of the geometric SMOS pixel mean turned out to be congruent with the respective radiometric averages over the working area. Compared to the pixel the sand fraction is lowered for the entire working area, while clay fraction and bulk density increase. The fractional shift in the soil texture is in line with the Danish soil grid by [45], though this soil type classification is not directly comparably with the absolute values of the FAO texture grids. The averages of the two in situ data sets are in comparable range, though naturally the network average shows a bit less sandy conditions. What clearly stands out is that the SMOS average sand fraction and bulk density values for the pixel are about $18 \%$ and $0.35 \mathrm{~g} / \mathrm{cm}^{3}$ lower than the in situ values, while for clay fraction it is about $8 \%$ higher. 


\section{E. Comparison of SMOS FMO land cover fractions (ECOCLIMAP) with CORINE Land Cover 2000}

Table III shows the FMO fractions (radiometric mean of the working area) of DGG 2002029 together with the land cover fractions of the CORINE Land Cover Classification 2000 averaged over the working area and the SMOS pixel (geometric mean). There are no distinct differences between the average CORINE land cover fractions for the working area and the SMOS pixel. As in case of soil properties, we expect the radiometric mean of the working area to be congruent with the pixel geometric mean. The FMO fractions assume a slightly higher portion of low vegetation and lower urban land and wetland parts than CORINE2000. However, these fractional shifts seem to be insignificant. Water body and wetland fractions which could significantly impact the emission only exhibit marginal parts. We thus conclude that the FMO fractions used in the SMOS retrieval are in good agreement with the average CORINE land cover fractions.

\section{F. Synthesis}

All findings from the extensive SMOS validation at the Danish site are compiled in Table IV. In the following they are discussed in a synthesized fashion in order to determine the most likely error sources for the encountered deviations out of the list of possible explanations introduced in Section I.

Preliminary inspection of the network and campaign measurements gave confidence in reliable data sets. The network subgroup analysis further consolidated our trust in a representative setup for large-scale applications. Furthermore, our results are well in range with worldwide $\mathrm{Cal} / \mathrm{Val}$ findings. Thus, we do not believe that the major discrepancies between the SMOS products and in situ data originate from pronounced faultiness of the latter.

With respect to the larger amplitudes in the retrieved SMOS soil moisture data, different measurement depths between in situ sensors $(\sim 0-5 \mathrm{~cm})$ and SMOS $(<5 \mathrm{~cm})$, and the corresponding faster and stronger response to wetting and drying at shallower depth, are a plausible explanation (e.g. [37], [38]. As suggested by [35]) ponding water on vegetation after excessive rain events could further contribute. This is to be investiaged at the Danish site. Meanwhile, distinct rain events not captured by individual network stations but integrated into the SMOS data are not expected to constitute a significant error source as the spatial rain variability turned out to be small within the Danish validation area.

Spatial scaling effects constitute a further issue. A two small amount or not representative set of in situ measurements can easily provoke a bias when aggregated at larger scales. [43] addressed the deviations when comparing airborne radiometer data with different footprints as were likewise encountered for the Danish site when comparing aggregated modeled in situ, EMIRAD and SMOS data. [40] noted that averaging in situ data over several stations clearly improved the temporal correlation with retrieved SMOS soil moisture compared to single stations. However, there was no significant change in the associated RMSE. Similarly, we found for our in situ network that none of the subgroups could explain the temporal dynamics significantly better than all stations together which increases the trust in the representatives of our data set. The bias became smaller for some subgroups (at the cost of lower correlation), but it remained notable in all cases. Furthermore, more sophisticated data averaging by using the EMIRAD antenna pattern to weight the average of the modeled in situ $T_{B}$ s nor the SMOS antenna pattern to 
estimate a weighted mean of EMIRAD data over the SMOS pixel did not improve the results over applying simple data averaging. Thus, while some scaling effects are certainly inherent in the data comparison, we believe that their contributions are of subordinate relevance to explain the deviances between SMOS and the in situ data.

The severe RFI contaminations reported for many sites constitute a further potential error source. In that case, the source of the biases would already be inherent in the corresponding L1 data rather than being caused somewhere within the retrieval. Beside the Danish Cal/Val site, the significant dry bias in soil moisture has also consistently been reported for other areas known to be heavily RFI-contaminated, such as the sites in Southern and Northern Germany. In our case the strong impact of RFI on data quality was demonstrated by the filtering of data which was independently detected as RFI. It significantly improved the agreement in the dynamics, while the significant dry bias persisted over the Danish site. Permanent low energy RFI sources that constantly superimpose the naturally emitted signal, but cannot clearly be identified individually could be a possible cause. This is suggested by [43] in case of the Northern German site, and would coincide with the fact that no such significant dry bias is detected at RFI "free" sites, such as West-Africa or the U.S. On the contrary, the dry bias is also observed in Australia where no heavy RFI impacts are expected. There, a presumption is that the SMOS retrieval is struggling with the extremely dry soils. Again, then it is inexplicable why the phenomenon is not likewise observed over the dry sites in Western Africa. At the Danish Cal/Val site the short campaign observation window accompanied by small temporal variability in soil moisture conditions as well as heavy RFI disturbances limited the extent of possible validation work at the brightness temperature level. Furthermore, model runs over longer time frames are confronted with large uncertainties inherent in the parameter settings. This renders this issue difficult to be tackled and requires more work to clarify the picture at the $1 \mathrm{C}$ level.

Finally, inaccuracies in the SMOS retrieval algorithm and related input could cause errors in the retrieved data products. As the retrieval is only based on the predominant land cover fraction while default contributions are assigned for the remaining fractions, it stands to reason that the overestimation of the initial soil moisture guess (ECMWF) could introduce bias in the retrieval. However, a sensitivity study by [37] showed the same retrieval results when the initial estimates were varied between 0 and $0.6 \mathrm{~m}^{3} / \mathrm{m}^{3}$. Likewise, [38] did not see a change in the bias between DGG nodes of significantly differing forest fractions with wetter conditions at the cost of the low vegetation fraction. Thus, a contribution to the retrieval offset is not expected.

There is a chance that the discrepancies between retrieved soil moisture/ $\tau_{N A D}$ and in situ data, respectively, are interlinked as they are simultaneously retrieved by an optimization approach. If they were correlated, then the observed overestimation of the vegetation optical depth could lead to underestimation in soil moisture. Indeed, over one U.S. watershed [37] found correspondence in the dynamic of SMOS retrieved soil moisture and $\tau_{N A D}$ along with a dry bias of the former. However, this particular watershed is situated in a mountainous area with topographical effects and very dry conditions. For the other watersheds they could not detect the same linkage between the retrieved parameters.

The $H_{R}$ roughness parameter which is consistently set to a value way below the values reported from the Cal/Val studies including the Danish site for all individual land cover types. Spatial scale dependency of $H_{R}$ was brought 
up as possible explanation for the lower SMOS values, as surfaces could appear significantly less rough from the large-distance perspective from space. Instead, [37] suggest that the too low $H_{R}$ could compensate the high $\tau_{N A D}$ values, and lead to low soil moisture. However, the soil moisture dry bias which is variable from one validation site to the other can probably not be explained by this constant parameter alone. In this context also the $N_{R H} / N_{R V}$ roughness parameter pair should be mentioned, for which a combination of $0 /-1$ instead of the SMOS default 2/0 increased the agreement between modeled in situ and EMIRAD $T_{B} \mathrm{~s}$. The complex interactions between these parameters accompanied by their non-linear behavior over spatial and temporal scales constitute severe challenges. Furthermore, our determined values currently compensate for the not considered impacts of the organic layer at the Danish site. Thus, the behavior of the parameters themselves as well as the role of the organic substrate clearly need further attention.

While the global surface temperature and land cover products used in the SMOS retrieval algorithm seem to be in good agreement with in situ data and regional information, respectively, the soil properties as well as the dielectric mixing model applied in the SMOS processor have to be considered as potential error sources. Replacing the Dobson with the Mironov dielectric mixing model is a good candidate for improvement as we obtained better agreement at the patch-scale. Likewise, the substitution of the soil property grids by local information could lead to advancement.

\section{Conclusions/OutLooK}

Since launch, SMOS has been acquiring soil moisture and vegetation optical thickness data which is currently subject to validation with in situ measurements across a range of climatic regions. The objective of this article was to compile previous validation results as well as present more in-depth analysis from the Danish validation site, covering SMOS pixel 2002029 in the Skjern River Catchment. In addition to retrieved parameters, the most sensitive parameters input to the SMOS retrieval algorithm were studied.

The worldwide more or less consistent SMOS validation findings are likewise encountered at the Danish site. The retrieved soil moisture data is promising as it well-captures the precipitation dynamics. However, the retrieved SMOS soil mositure exhibits larger amplitudes and shows a significant dry bias compared to in situ data. The retrieved SMOS vegetation optical depth seems to overestimate true conditions and is accompanied by too high day to day variability to be explained by vegetation changes, as well as a lack of seasonal trend.

Several possible error sources for the observed deviations are currently under discussion, and it is probable that their respective contributions depend on the prevailing environmental conditions and the measurement setups of the individual $\mathrm{Cal} / \mathrm{Val}$ sites.

At the Danish site the most likely error sources were determined as the following:

- An applied SMOS data filter using two criteria from the L2 product $\left(X \_S W A T H<10000\right.$ and $C H I 2 \_P>$ 0.5) turned out to be in good agreement with an RFI detection scheme based on L1A data. This indicates that strong RFI contamination was eliminated prior to data comparison. The filtering improved the $R^{2}$ between retrieved soil moisture and the in situ network average from 0.49 to 0.61 , while the bias did not change 
significantly (from -0.092 to $-0.087 \mathrm{~m}^{3} / \mathrm{m}^{3}$ ). The remaining bias could be caused by RFI from permanent low energy sources still present in the data, suggesting that the error is already inherent in the L1C data.

- There is a chance that the high retrieved $\tau_{N A D}$ and the low retrieved soil moisture are linked. A further possibility is compensation of the high $\tau_{N A D}$ for the $H_{R}$ roughness parameter, which could cause low soil moisture values. $H_{R}$ was found to be significantly lower in the SMOS retrieval than estimated in situ within the studied SMOS pixel 2002029. Furthermore, up to this point, only in situ data from the mineral soils was considered in our validation activities, resulting also in compensation of the $\tau_{N A D}$ and $H_{R}$ parameters for this significantly wetter substrate.

- Comparison between average in situ soil properties with the SMOS FAO/ISLSCP data sets for DGG node 2002029 revealed clear differences with average SMOS sand fraction and bulk density being about $18 \%$ and $0.35 \mathrm{~g} / \mathrm{cm}^{3}$ lower, while the clay fraction being about $8 \%$ higher. Furthermore, the Mironov dielectric mixing model outperformed the Dobson model in a small-scale comparison.

- With respect to the larger amplitudes in the retrieved SMOS soil moisture data, different measurement depths between in situ sensors and SMOS are currently the most plausible explanation.

The unsolved RFI issues as well as the complex interactions between SMOS algorithm parameters accompanied by non-linear behavior over spatial and temporal scales constitute notable challenges to be mastered and more work is needed to enhance clarification. Further investigations at the Danish SMOS Cal/Val site will concentrate on investigations of the SMOS L1C - L2 data relation over longer time frames as well as site-specific adjustments in the SMOS processor. Furthermore, the potential differences in sampling depth and the role of the organic matter will be studied.

\section{ACKNOWLEDGMENT}

The project is funded by the Villum Foundation and the Technical University of Denmark. Special thank goes to the SMOS team at CESBIO and Jean-Pierre Wigneron for providing model codes as well as constructive discussions.

\section{REFERENCES}

[1] Y. Kerr, P. Waldteufel, J.-P. Wigneron, J.-M. Martinuzzi, J. Font, and M. Berger, "Soil moisture retrieval from space: The soil moisture and ocean salinity (smos) mission," IEEE Transactions on Geoscience and Remote Sensing, vol. 39, no. 8, 2001.

[2] Y. H. Kerr, P. Waldteufel, J.-P. Wigneron, S. Delwart, F. Cabot, J. Boutin, M. Escorihuela, J. Font, N. Reul, C. Gruhier, E. J. S., M. R. Drinkwater, A. Hahne, M. Martin-Neira, and S. Mecklenburg, "The smos mission: New tool for monitoring key elements of the global water cycle," Proceedings of the IEEE, vol. 98, no. 5, pp. 666-687, May 2010.

[3] Y. Kerr, "Soil moisture from space: Where are we?" Hydrogeology Journal, vol. 15, pp. 117-120, 2007.

[4] W. Wagner, G. Blöschl, P. Pampaloni, J.-C. Calvet, B. Bizzarri, J.-P. Wigneron, and Y. Kerr, "Operational readiness of microwave remote sensing of soil moisture for hydrologic applications," Nordic Hydrology, vol. 38, no. 1, pp. 1-20, 2007.

[5] Y. Kerr, P. Waldteufel, P. Richaume, P. Davenport, P. Ferrazzoli, and J.-P. Wigneron, "Smos level 2 processor soil moisture algorithm theoretical basis document (atbd)," CBSA, UoR, TV and INRA, Toulouse, Tech. Rep. SO-TN-ARR-L2PP-0037, V3.4, 24/01/2011 2011. [Online]. Available: http://www.cesbio.ups-tlse.fr/fr/indexsmos.html 
[6] J.-P. Wigneron, Y. Kerr, P. Waldteufel, K. Saleh, Escorihuela, M.-J., P. Richaume, P. Ferrazzoli, P. de Rosnay, R. Gurney, J.-C. Calvet, J. Grant, M. Guglielmetti, B. Hornbuckle, C. Mätzler, T. Pellarin, and M. Schwank, "L-band microwave emission of the biosphere (1-meb) model: Description and calibration against experimental data sets over crop fields," Remote Sensing of Environment, vol. 107, pp. 639-655, 2007.

[7] S. Delwart, C. Bouzinac, P. Wursteisen, M. Berger, M. Drinkwater, M. Martin-Neira, and H. Kerr, Yann, "Smos validation and the cosmos campaign," IEEE Transactions on Geoscience and Remote Sensing, vol. 46, no. 3, pp. 695-704, 2008.

[8] T. Schmugge, J. Wang, and G. Asrar, "Results from the push broom microwave radiometer flights over the konza prairie in 1985," IEEE Transactions on Geoscience and Remote Sensing, vol. 26, no. 5, 1988.

[9] T. Jackson, D. Le Vine, C. Swift, T. Schmugge, and F. Schiebe, "Large area mapping of soil moisture using the estar passive microwave radiometer in washita'92," Remote Sensing of Environment, vol. 53, pp. 27-37, 1995.

[10] T. Jackson, D. Le Vine, A. Hsu, A. Oldak, P. Starks, C. Swift, J. Isham, and M. Haken, "Soil moisture mapping at regional scales using microwave radiometry: The southern great plains hydrology experiment," IEEE Transactions on Geoscience and Remote Sensing, vol. 37, no. 5, 1999.

[11] R. Panciera, J. Walker, J. Kalma, E. Kim, J. Hacker, O. Merlin, M. Berger, and N. Skou, "The nafe'05/cosmos data set: Toward smos soil moisture retrieval, downscaling, and assimilation,” IEEE Transactions on Geoscience and Remote Sensing, vol. 46, no. 3, pp. 736-745, 2008.

[12] O. Merlin, J. Walker, J. Kalma, E. Kim, J. Hacker, R. Panciera, R. Young, G. Summerell, J. Hornbuckle, M. Hafeez, and T. Jackson, "The nafe'06 data set: Towards soil moisture retrieval at intermediate resolution," Advances in Water Resources Research, vol. 31, pp. 1444-1455, 2008.

[13] S. Peischl, J. P. Walker, C. Rudiger, Y. Nan, Y. Kerr, and E. Kim, "The aaces field experiments: Smos calibration and validation across the murrumbidgee river catchment," In Prep.

[14] J. T. Dall'Amico, F. Schlenz, A. Loew, and W. Mauser, "Smos soil moisture validation: Status at the upper danube cal/val site eight monghts after launch," in IEEE International Geoscience and Remote Sensing Symposium (IGARSS), Honolulu, Hawaii, USA, 2010, pp. $3801-3804$.

[15] J. Kainulainen, K. Rautiainen, P. Sievinen, J. Seppaenen, E. Rouhe, M. Hallikainen, J. Dall'Amico, F. Schlenz, A. Loew, S. Bircher, and C. Montzka, "Smos calibration and validation activities with airborne interferometric radiometer hut-2d during spring 2010," in Geoscience and Remote Sensing Symposium (IGARSS), Honolulu, HI, USA, 25-30 July 2010, pp. 702-705.

[16] C. Albergel, E. Zakharova, J.-C. Calvet, M. Zribi, M. Pardé, J.-P. Wigneron, N. Novello, Y. Kerr, A. Mialon, and N. Fritz, "A first assessment of the smos data in southwestern france using in situ and airborne soil moisture estimates: the carols airborne campaign," Remote Sensing of Environment, vol. 115, pp. 2718-2728, 2011.

[17] A. Kontu, J. Lemmetyinen, J. Pulliainen, K. Rautiainen, J. Kainulainen, and J. Seppaenen, "L-band measurements of boreal soil," in IEEE International Geoscience and Remote Sensing Symposium (IGARSS), no. Digital Object Identifier: 10.1109/IGARSS.2010.5654116, 2010, pp. 706-709.

[18] D. Bosch, V. Lakshmi, T. Jackson, M. Choi, and J. Jacobs, "Large scale measurements of soil moisture for validation of remotely sensed data: Georgia soil moisture experiment of 2003," Journal of Hydrology, vol. 323, pp. 120-137, 2006.

[19] G. L. Schaefer, M. H. Cosh, and T. J. Jackson, "The usda natural resources conservation service soil climate analysis network (scan)," Journal of Atmospheric and Oceanic Technology, vol. 24, pp. 2073-2077, 2007.

[20] T. J. Jackson, M. H. Cosh, R. Bindlish, P. J. Starks, D. D. Bosch, M. Seyfried, D. C. Goodrich, M. S. Moran, and J. Du, "Validation of advanced microwave scanning radiometer soil moisture products," IEEE Transactions on Geoscience and Remote Sensing, vol. 48, no. 12, pp. 4256-4272, December 2010.

[21] C. Champagne, A. Berg, J. Belanger, H. McNairn, and R. de Jeu, "Evaluation of soil moisture derived from passive microwave remote sensing over agricultural sites in canada using ground-based soil moisture monitoring networks," International Journal of Remote Sensing, vol. 31, no. 14, pp. 3669-3690, 2010.

[22] J. P. Walker, G. R. Willgoose, and J. D. Kalma, "The nerrigundah data set: Soil moisture patterns, soil characteristics, and hydrological flux measurements," Water Resources Research, vol. 37, no. 11, pp. 2653-2658, November 2001.

[23] P. de Rosnay, C. Gruhier, F. Timouk, F. Baup, E. Mougin, P. Hiernaux, L. Kergoat, and V. LeDantec, "Multi-scale soil moisture measurements at the gourma meso-scale site in mali," Journal of Hydrology, vol. 375, pp. 241-252, 2009. 
[24] J. Martinez-Fernandez and A. Ceballos, "Temporal stability of soil moisture in a large-field experiment in spain," Soil Science Society of America, vol. 67, pp. 1647-1656, 2003.

[25] J.-C. Calvet, N. Fritz, F. Froissard, D. Suquia, A. Petitpa, and B. Piguet, "In situ soil moisture observations for the cal/val of smos: the smosmania network," in IEEE International Geoscience and Remote Sensing Symposium (IGARSS), Barcelona, Spain, July 23-27 2007, pp. 1196-1199.

[26] L. Krauss, C. Hauck, and C. Kottmeier, "Spatio-temporal soil moisture variability in southwest germany observed with a new monitoring network within the cops domain," Meteorologische Zeitschrift, vol. 19, no. 6, pp. 523-537, 2010.

[27] H. Bogena, M. Herbst, J. A. Huisman, U. Rosenbaum, A. Weuthen, and H. Veerecken, "Potential of wireless sensor networks for measuring soil water content variability," Vadose Zone Journal, vol. 9, pp. 1002-1013, 2010.

[28] J. S. Famiglietti, J. W. Rudnicki, and M. Rodell, "Variability in surface moisture content along a hillslope transect: Rattlesnake hill, texas," Journal of Hydrology, vol. 210, pp. 259-281, 1998.

[29] B. P. Mohanty, T. H. Skaggs, and J. S. Famiglietti, "Analysis and mapping of field-scale soil moisture variability using high-resolution, ground-based data during the southern great plains 1997 (sgp97) hydrology experiment," Water Resources Research, vol. 36, no. 4, pp. 1023-1031, 2000.

[30] A. W. Western, R. B. Grayson, and G. Bloeschl, "Scaling of soil moisture: a hydrologic perspective," Annual Review of Earth and Planetary Sciences, vol. 30, pp. 149-180, 2002.

[31] K. Jensen and T. Illangasekare, "Hobe: A hydrological observatory," Vadose Zone Journal, vol. 10, pp. 1-7, 2011.

[32] S. Bircher, N. Skou, K. H. Jensen, J. P. Walker, and L. Rasmussen, "A soil moisture and temperature network for smos validation in the skjern river catchment, western denmark," Hydrology and Earth System Sciences, submitted.

[33] S. Bircher, J. Balling, and N. Skou, "Smos validation activities at different scales in the skjern river catchment, western dk," in ESA Living Planet Symposium, H. Lacoste-Francis, Ed., ESA. Bergen, Norway: ESA communications, 28. June - 02. July 2010.

[34] S. Bircher, J. E. Balling, N. Skou, and Y. Kerr, "Validation of smos brightness temperatures during the hobe airborne campaign, western denmark," IEEE Transactions on Geoscience and Remote Sensing, Accepted.

[35] C. Ruediger, J. P. Walker, Y. H. Kerr, A. Mialon, O. Merlin, and E. J. Kim, "Validation of the level 1c and level 2 smos products with airborne and ground-based observations," in International Congress on Modelling and Simulation (MODSIM), Perth, Australia, December 12-16 2011.

[36] J. T. Dall'Amico, F. Schlenz, A. Loew, and W. Mauser, "First results of smos soil moisture validation in the upper danube catchment," IEEE Transactions on Geoscience and Remote Sensing, Accepted.

[37] T. J. Jackson, R. Bindlish, M. Cosh, T. Zhao, P. J. Starks, D. D. Bosch, M. Seyfried, S. M. Moran, D. Goodrich, Y. Kerr, and D. Leroux, "Validation of soil moisture and ocean salinity (smos) soil moisture over watershed networks in the u.s." IEEE Transactions on Geoscience and Remote Sensing, Accepted.

[38] A. Al Bitar, D. Leroux, Y. Kerr, O. Merlin, P. Richaume, A. Sahoo, and E. F. Wood, "Evaluation of smos soil moisture products over continental us using the scan/snotel network," IEEE Transactions on Geoscience and Remote Sensing, In Review.

[39] D. J. Leroux, Y. H. Kerr, A. Al Bitar, C. Gruhier, R. Bindlish, T. J. Jackson, B. Berthelot, and G. Portet, "Comparison between smos and other satellite and model forecast products," Remote Sensing of Environment, in review.

[40] C. Gruhier, T. Pellarin, P. de Rosnay, and Y. Kerr, "Smos soil moisture product evaluation over west-africa at local and regional scale," Remote Sensing of Environment, In Review.

[41] E. Daganzo, J. Pla, Y. Kerr, M. Martin-Neira, R. Oliva, E. Marelli, S. Mecklenburg, B. Rommen, M. Brown, P. Richaume, and C. Gruhier, "Characterisation of smos $\mathrm{rf}$ interferences in the 1400-1427 mhz band as detected during the commissioning phase," in OCOSS 2010 , Brest, France, 2010.

[42] N. Skou, J. Balling, S. S. Søbjærg, and S. S. Kristensen, "Surveys and analysis of rfi in the smos context," in Proceedings of IGARSS, July 2010c, pp. 2011-2014.

[43] C. Montzka, H. Bogena, L. Weihermüller, F. Jonard, C. Bouzinac, J. Kainulainen, J. E. Balling, A. Loew, J. Dall'Amico, E. Rouhe, J. Vanderborght, and H. Vereecken, "Brightness temperature validation at different scales during the smos validation campaign in the rur and erft catchments, germany," Transactions on Geoscience and Remote Sensing, Accepted, special issue on "SMOS - instrument performance and first results". 
[44] F. Schlenz, J. T. Dall'Amico, A. Loew, and W. Mauser, "Uncertainty assessment of the smos validation in the upper danube catchment," IEEE Transactions on Geoscience and Remote Sensing, Accepted.

[45] M. H. Greve, M. B. Greve, P. Bøcher, T. Balstrøm, H. Breuning-Madsen, and L. Krogh, "Generating a danish raster-based topsoil property map combining choropleth maps and point information," Danish Journal of Geography, vol. 107, no. 2, pp. 1-12, 2007.

[46] M. Scharling, "Klimagrid danmark nedboer 10 x 10 km (ver.2)," Danish Meteorological Institute, Copenhagen, Technical Report 99-15, 1999, p. 18 (in Danish).

[47] F. Vejen, H. Madsen, and P. Allerup, "Korrektion for fejlkilder på måling af nedbør - korrektionsprocenter ved udvalgte stationer 19891999,” Danish Meteorological Institute, Copenhagen, Technical Report 00-20, 2000, p. 53 (in Danish).

[48] L. Brocca, F. Melone, T. Moramarco, and R. Morbidelli, "Spatial-temporal variability of soil moisture and its estimation across scales," Water Resources Research, vol. 46, pp. W02 516+, 2010.

[49] N. Skou, S. S. Søbjærg, J. Balling, S. S. Kristensen, and A. Kusk, "Emirad-2 and its use in the smos cal/val campaign,” DTU Space, Kgs. Lyngby, Denmark, Tech. Rep. AR 502, June 2010a.

[50] Y. Kerr, P. Waldteufel, P. Richaume, A. Mahmoodi, J.-P. Wigneron, P. Ferrazzoli, A. Al bitar, F. Cabot, D. Leroux, A. Mialon, and S. Delwart, "The smos soil moisture retrieval algorithm," IEEE Transactions on Geoscience and Remote Sensing, vol. This issue, In Review.

[51] B. Bengoa, M. Zapata, C. Cabeza, and M. Rodriguez, "Smos level 2 processor and auxiliary data products specifications," INDRA, Madrid, Tech. Rep. SO-TN-IDR-GS-0006, V5.3, 23/12/2010 2010. [Online]. Available: http://www.cesbio.ups-tlse.fr/fr/indexsmos.html

[52] M. Dobson, F. Ulaby, M. Hallikainen, and M. El-Reyes, "Microwave dielectric behavior of wet soil - part ii: Dielectric mixing models," IEEE Transactions on Geoscience and Remote Sensing, vol. 23, pp. 35-46, 1985.

[53] N. Peplinski, F. Ulaby, and M. Dobson, "Dielectric properties of soils in the 0.3-1.3-ghz range," IEEE Transactions on Geoscience and Remote Sensing, vol. 33, no. 3, pp. 803-807, 1995.

[54] V. Mironov, M. Dobson, V. Kaupp, S. Komarov, and V. Kleshchenko, "Generalized refractive mixing dielectric model for moist soils," IEEE Transactions on Geoscience and Remote Sensing, vol. 42, no. 4, pp. 773-785, 2004.

[55] M. Pardé, J.-P. Wigneron, P. Waldteufel, Y. Kerr, A. Chanzy, S. S. Søbjærg, and N. Skou, "N-parameter retrievals from 1-band microwave observations acquired over a variety of crop fields," IEEE Transactions on Geoscience and Remote Sensing, vol. 42, no. 6, pp. 1168-1178, June 2004.

[56] J. Grant, K. Saleh-Contell, J.-P. Wigneron, M. Guglielmetti, Y. Kerr, M. Schwank, N. Skou, and V. de Griend A., "Calibration of the 1-meb model over a coniferous and a deciduous forest," IEEE Transactions on Geoscience and Remote Sensing, vol. 46, no. 3, pp. 808-818, March 2008.

[57] R. Panciera, J. Walker, and O. Merlin, "Improved understanding of soil surface roughness parameterization for 1-band passive microwave soil moisture retrieval," IEEE Geoscience and Remote Sensing Letters, vol. 6, no. 4, pp. 625-629, October 2009a.

[58] A. Cano, K. Saleh, J.-P. Wigneron, C. Antolín, J. E. Balling, Y. Kerr, A. Kruszewski, C. Millán-Scheiding, S. Schmidl Søbjærg, N. Skou, and E. López-Baeza, "The smos mediterranean ecosystem 1-band characteristation experiment (melbex-i) over natural shrubs," Remote Sensing of Environment, vol. 114, pp. 844-853, 2010.

[59] R. Panciera, J. Walker, J. Kalma, E. Kim, K. Saleh, and J.-P. Wigneron, "Evaluation of the smos 1-meb passive microwave soil moisture retrieval algorithm," Remote Sensing of Environment, vol. 113, pp. 435-444, 2009b.

[60] K. Saleh, Y. Kerr, P. Richaume, M.-J. Escorihuela, R. Panciera, S. Delwart, G. Boulet, P. Maisongrande, J. Walker, P. Wursteisen, and J.-P. Wigneron, "Soil moisture retrievals at 1-band using a two-step inversion approach (cosmos/nafe'05 experiment)," Remote Sensing of Environment, vol. 113, pp. 1304-1312, 2009.

[61] E. Anterrieu, "On the detection and quantification of rfi in 11a signals provided by smos," IEEE Transactions on Geoscience and Remote Sensing, vol. 49, no. 10, pp. 3986-3992, October 2011, digital Object Identifier : 10.1109/TGRS.2011.2136350.

[62] M. Escorihuela, A. Chanzy, J. Wigneron, and Y. Kerr, "Effective soil moisture sampling depth of l-band radiometry: A case study," Remote Sensing of Environment, vol. 114, pp. 995-1001, 2010.

[63] T. Jackson and T. Schmugge, "Vegetation effects on the microwave emission of soils," Remote Sensing of Environment, vol. 36, pp. 203-212, 1991.

[64] K. Saleh, J.-P. Wigneron, P. Waldteufel, P. de Rosnay, M. Schwank, J.-C. Calvet, and Y. Kerr, "Estimates of surface soil moisture under grass covers using 1-band radiometry," Remote Sensing of Environment, vol. 109, pp. 42-53, 2007. 
6

7

8

9

10

11

12

13

14

15

16

17

18

19

20

21

22

23

24

25

26

27

28

29

30

31

32

33

34

35

36

37

38

39

40

41

42

43

44

45

46

47

48

49

50

51

52

53

54

55

56

57

58

59

60
IEEE TRANSACTIONS ON GEOSCIENCE AND REMOTE SENSING, VOL. 6, NO. 1, JANUARY 2007

20

[65] EEA. (2005, 02.03.2006) Corine land cover 2000 (clc2000) $100 \mathrm{~m}$ - version 8/2005. European Environmental Agency. Copenhagen. [Online]. Available: http://dataservice.eea.eu.int/ 
TABLE I

STATISTICS (RMSE, BIAS, $R^{2}$ ) OF COMPARISON BETWEEN AVERAGE 0-5 CM NETWORK SOIL MOISTURE AND RETRIEVED SMOS DATA OF GRID NODE 2002029 FOR THE ENTIRE YEAR 2010, FOR UNFILTERED AND FILTERED SMOS DATA, AND NETWORK DATA GROUPED INTO SOIL TYPE CLASSES, LAND COVER CLASSES, COMPOSITE CLASSES, AND FOUR SEASONS, FOR FILTERED SMOS DATA. SPECIFICATIONS ON THE SUBGROUPS AND RESPECTIVE FRACTIONS [\%] ARE INDICATED. TS = TOPSOIL, SS = SUBSOIL.

\begin{tabular}{|c|c|c|c|c|c|c|}
\hline Network data & Subgroups & Specification & Fraction & RMSE & BIAS & $R^{2}$ \\
\hline All unfiltered & & & & 0.102 & -0.092 & 0.49 \\
\hline All filtered & & & & 0.094 & -0.087 & 0.61 \\
\hline \multirow[t]{4}{*}{ Soil types } & Sand & $75-100 \%$ sand, $0-5 \%$ clay & 80 & 0.087 & -0.079 & 0.61 \\
\hline & Loamy sand & $65-95 \%$ sand, $5-10 \%$ clay & 13.3 & 0.103 & -0.089 & 0.35 \\
\hline & Sandy loam & $55-90 \%$ sand, $10-15 \%$ clay & 3.3 & 0.152 & -0.148 & 0.62 \\
\hline & Clay & $40-85 \%$ sand, $15-25 \%$ clay & 3.3 & 0.226 & -0.217 & 0.26 \\
\hline \multirow[t]{6}{*}{ Land cover } & Heath & & 13.3 & 0.144 & -0.138 & 0.5 \\
\hline & Forest & & 13.3 & 0.071 & -0.057 & 0.55 \\
\hline & Agriculture winter cereal & & 16.7 & 0.085 & -0.077 & 0.55 \\
\hline & Agriculture grass & & 16.7 & 0.122 & -0.117 & 0.59 \\
\hline & Agriculture potato & & 10 & 0.057 & -0.034 & 0.5 \\
\hline & Agriculture spring cereal & & 30 & 0.076 & -0.061 & 0.41 \\
\hline \multirow[t]{6}{*}{ Composite classes } & 612 & Heath, topsoil sand, subsoil sand & 13.3 & 0.144 & -0.138 & 0.5 \\
\hline & 512 & Forest, topsoil sand, SS sand & 13.3 & 0.071 & -0.057 & 0.55 \\
\hline & 211 & Agriculture, TS sand, SS clay & 6.7 & 0.150 & -0.146 & 0.66 \\
\hline & 212 & Agriculture, TS sand, SS sand & 53.3 & 0.068 & -0.058 & 0.59 \\
\hline & 232 & Agriculture, TS loamy sand, SS sand & 6.7 & 0.190 & -0.179 & 0.19 \\
\hline & 292 & Agriculture, TS organic-rich, SS sand & 6.7 & 0.098 & -0.090 & 0.47 \\
\hline \multirow[t]{4}{*}{ Seasons } & Spring & & & 0.102 & -0.098 & 0.39 \\
\hline & Summer & & & 0.085 & -0.078 & 0.63 \\
\hline & Fall & & & 0.095 & -0.086 & 0.6 \\
\hline & Winter & & & $\mathrm{NaN}$ & $\mathrm{NaN}$ & $\mathrm{NaN}$ \\
\hline
\end{tabular}

\section{TABLE II}

SOIL PROPERTIES (SAND AND CLAY FRACTIONS [\%], BULK DENSITY [G/ $\mathrm{cm}^{3}$ ]) OF SMOS GRID NODE 2002029: FAO/ISLSCP DATA USED IN THE SMOS RETRIEVAL ALGORITHM, GEOMETRIC AND RADIOMETRIC MEAN OF THE WORKING AREA (= GEOMETRIC MEAN PIXEL), AND 0-5 CM IN SITU DATA, AVERAGE OF NETWORK SAMPLES AND WEIGHTED AVERAGE OF CAMPAIGN PATCH SAMPLES (77\% AGRICULTURE, $9 \%$ HEATH, 15\% FOREST).

\begin{tabular}{llll}
\hline & Sand & Clay & Bulk density \\
\hline SMOS geometric mean working area & 58 & 17 & 1.05 \\
SMOS radiometric mean working area* & 71 & 11 & 0.88 \\
Network samples 0-5 cm average & 87 & 4 & 1.22 \\
Campaign samples 0-5 cm weighted average & 90 & 3 & 1.24 \\
\hline
\end{tabular}


TABLE III

LAND COVER FRACTIONS [\%] OF SMOS GRID NODE 2002029: FMO FRACTIONS (ECOCLIMAP) USED IN THE SMOS RETRIEVAL ALGORITHM, RADIOMETRIC MEAN OF THE WORKING AREA, AND CORINE LAND COVER 2000 FRACTIONS, GEOMETRIC MEAN OF WORKING AREA AND PIXEL.

\begin{tabular}{llll}
\hline & FMO/ECOCLIMAP & CORINE2000 & \\
& Working area & Working area & Pixel \\
\hline Low vegetation (FNO) & 84.16 & 82.32 & 80.36 \\
Forest (FFO) & 14.45 & 10.5 & 14.36 \\
Urban land (FEU) & 0.55 & 4.78 & 3.21 \\
Wetlands (FWL) & 0.43 & 1.47 & 1.81 \\
Open water (FWO) & 0.4 & 0.87 & 0.26 \\
\hline
\end{tabular}

TABLE IV

SUMMARY OF VALIDATION RESULTS FOR SMOS L1C, L2 INITIAL AND RETRIEVED DATA IN COMPARISON WITH IN SITU DATA: $T_{B}$, SOIL MOISTURE, REAL PART OF DIELECTRIC CONSTANT, SURFACE TEMPERATURE, $\tau_{N A D}, H_{R}, N_{R H} / N_{R V}$, SOIL PROPERTIES, DIELECTRIC MIXING MODEL, AND LAND COVER FRACTIONS. POTENTIAL ERROR SOURCES ARE DEPICTED IN BOLD, CASES WITH SHORT COMPARISON PERIOD IN ITALIC LETTERS.

\begin{tabular}{|c|c|c|c|}
\hline & SMOS L1C & SMOS L2 inital & SMOS L2 retrieved \\
\hline$T_{B}$ & $\begin{array}{l}\text { offset, large uncertainty, } \\
\text { scale effects? }\end{array}$ & & \\
\hline Soil moisture & & clear trend, too high & clear trend, too low \\
\hline Real dielectric constant & & & clear trend, too low \\
\hline Surface temparature & & clear trend, same range & \\
\hline$\tau_{N A D}$ & & clear trend, same range & trend, too high, noisy \\
\hline$H_{R}$ & & too low or $f($ scale $)$ ? & \\
\hline$N_{R H} / N_{R V}$ & & $0 /-1$ better $2 / 0$ & \\
\hline Land cover fractions & & in accord with CORINE2000 & \\
\hline Soil properties & & sand\%/bulk density too low, clay\% too high & \\
\hline Dielectric mixing model & & Mironov better Dobson (2x2 $\mathrm{km}$ scale) & \\
\hline
\end{tabular}



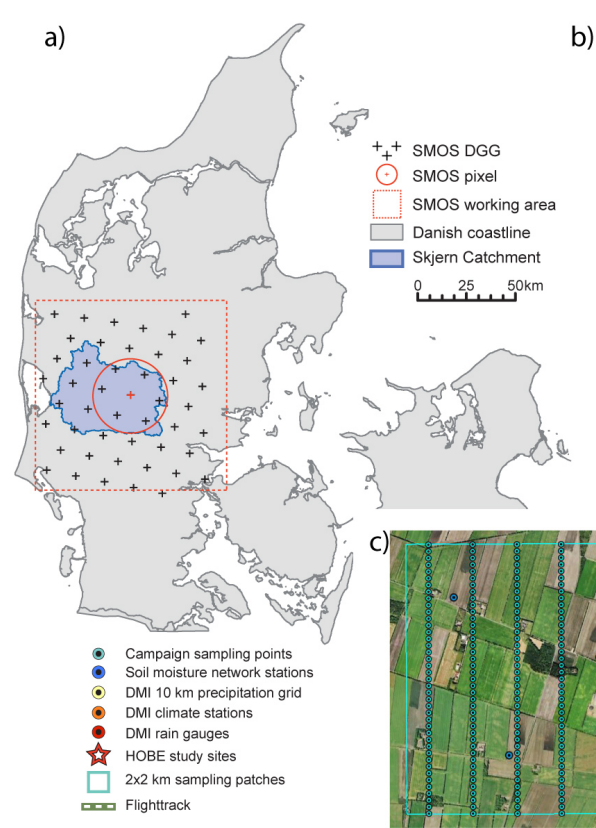

b)
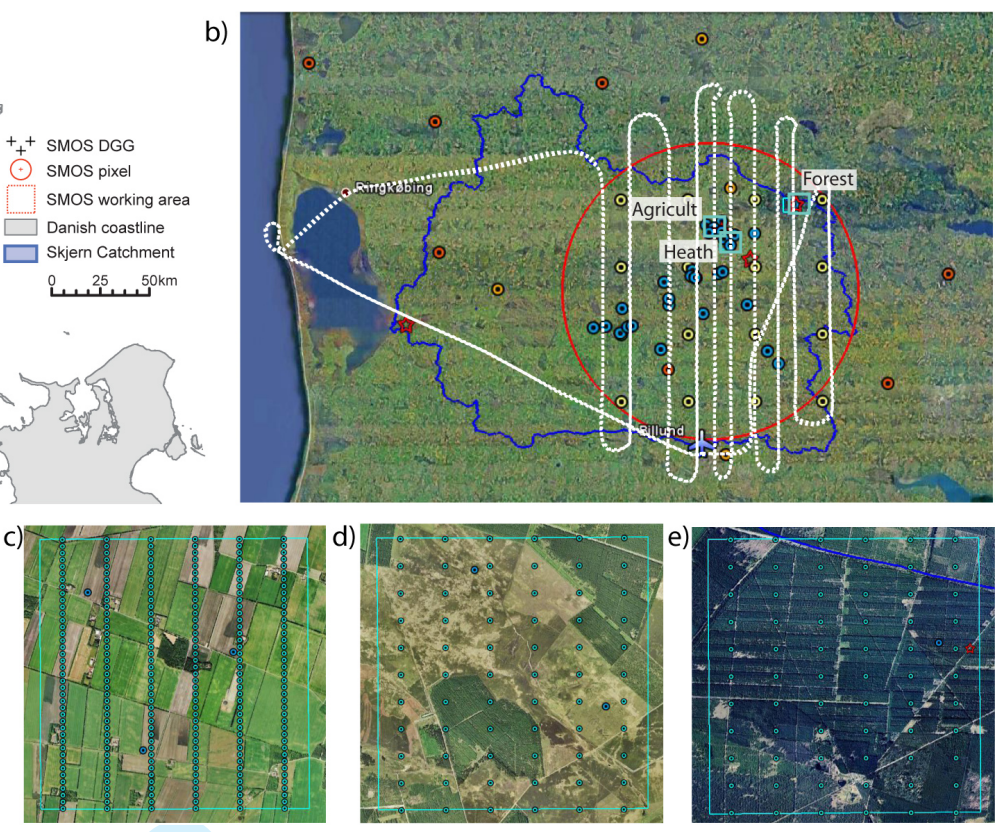

Fig. 1. Overview over the validation site: a) Danish coastline, Skjern River Catchment, SMOS pixel (44 km diameter) and working area $(123 \times 123 \mathrm{~km})$ around grid node 2002029 , b) HOBE study sites, campaign flight tracks and sampling patches, soil moisture network stations, DMI climate stations, rain gauges and $10 \mathrm{~km}$ precipitation grid, c) agriculture, d) heath, and e) forest campaign ground sampling transects within respective $2 \times 2 \mathrm{~km}$ patches.

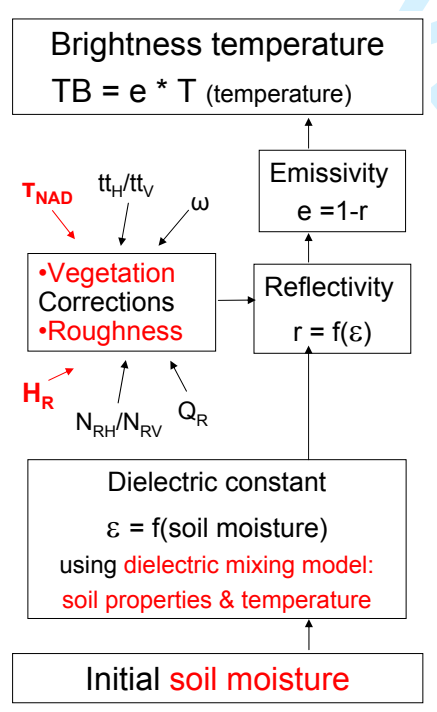

Fig. 2. Simplified schematic illustration of the L-band Microwave Emission of the Biosphere, L-MEB, forward model. 

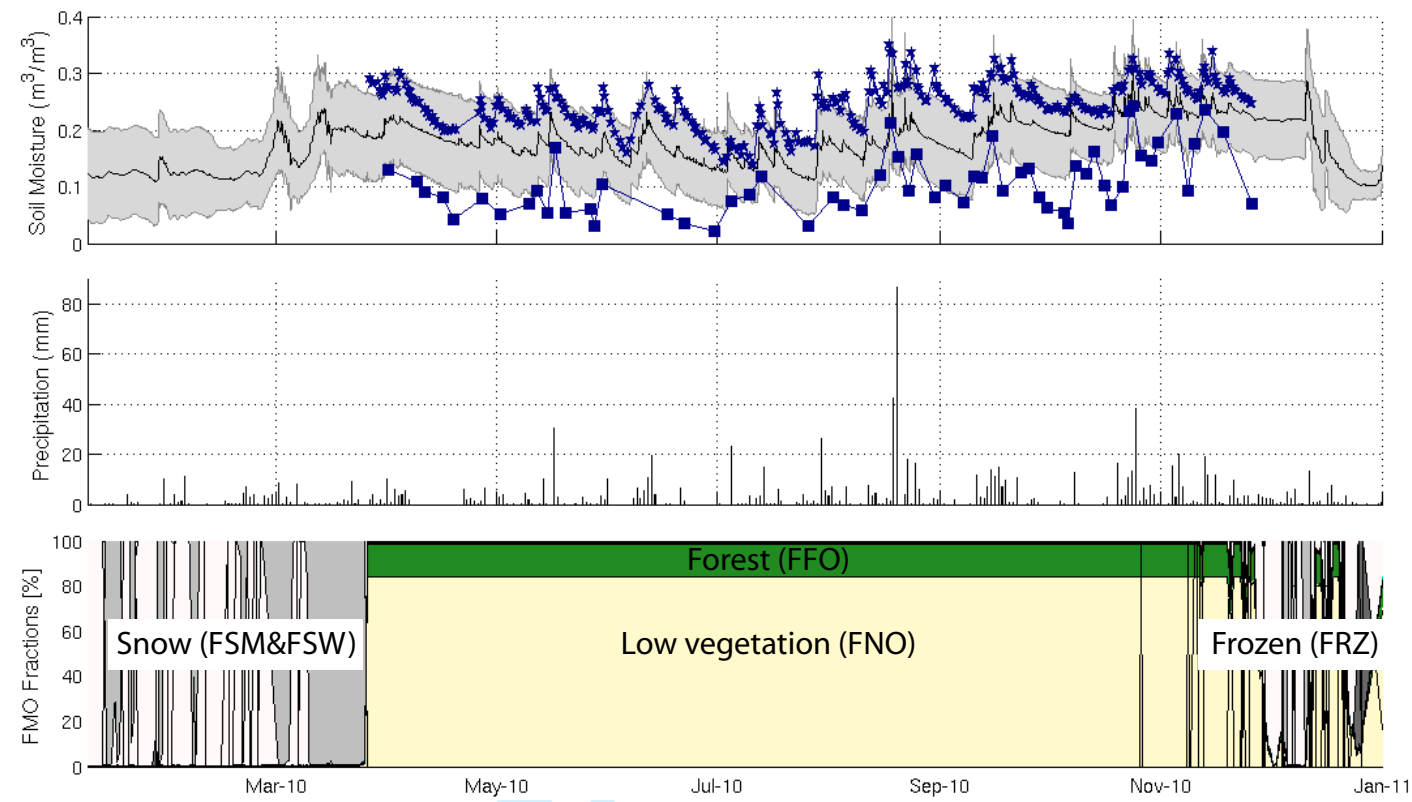

Fig. 3. Soil moisture (top panel): Average and standard deviation of 0-5 cm network soil moisture (black line and grey-shaded region), and initial/filtered retrieved SMOS L2 soil moisture (dark blue star/square) of grid node 2002029; mean of daily precipitation of $10 \mathrm{~km}$ precipitation grid nodes contained within the SMOS pixel (center panel); SMOS FMO fractions (bottom panel); January - December 2010.

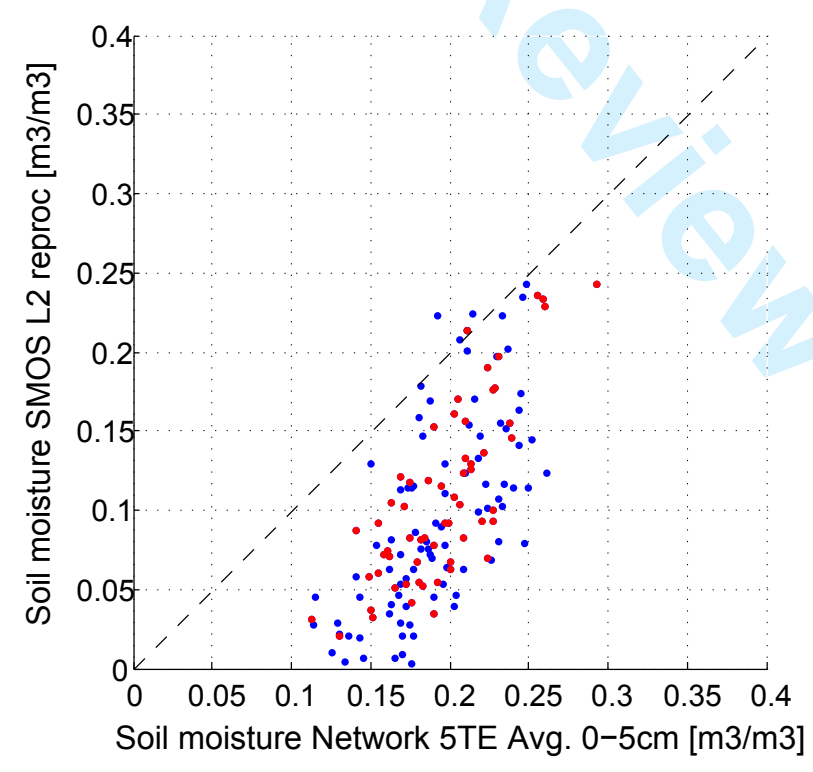

Fig. 4. Average 0-5 cm network soil moisture plotted against the filtered (red) and unfiltered (blue) retrieved SMOS data of grid node 2002029 for the entire year 2010 . 


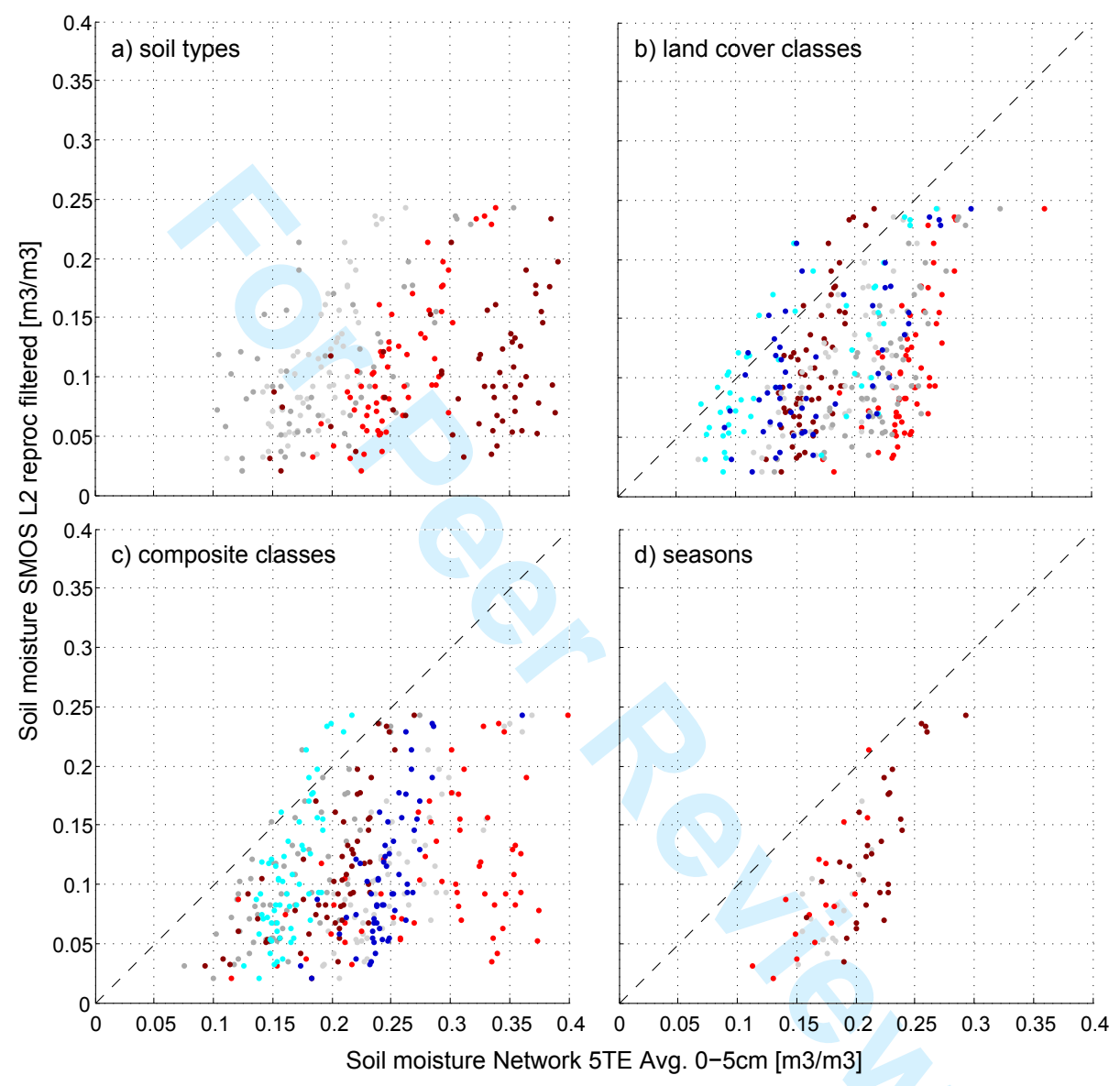

Fig. 5. Average 0-5 cm network soil moisture plotted against the filtered retrieved SMOS data of grid node 2002029 for the entire year 2010 , with network data grouped into (a) soil type classes: sand (light grey), loamy sand (dark grey), sandy loam (red), clay (dark red);(b) land cover classes: heath (red), forest (dark red), winter cereal (light grey), agriculture grass (dark grey), potato (light blue), spring cereal (dark blue) ;(c) composite classes: 211 (light grey), 212 (dark grey), 232 (red), 292 (dark red), 512 (light blue), 612 (dark blue); (d) four seasons: spring (light grey), summer (red), fall (dark red), winter (no retrieval). 

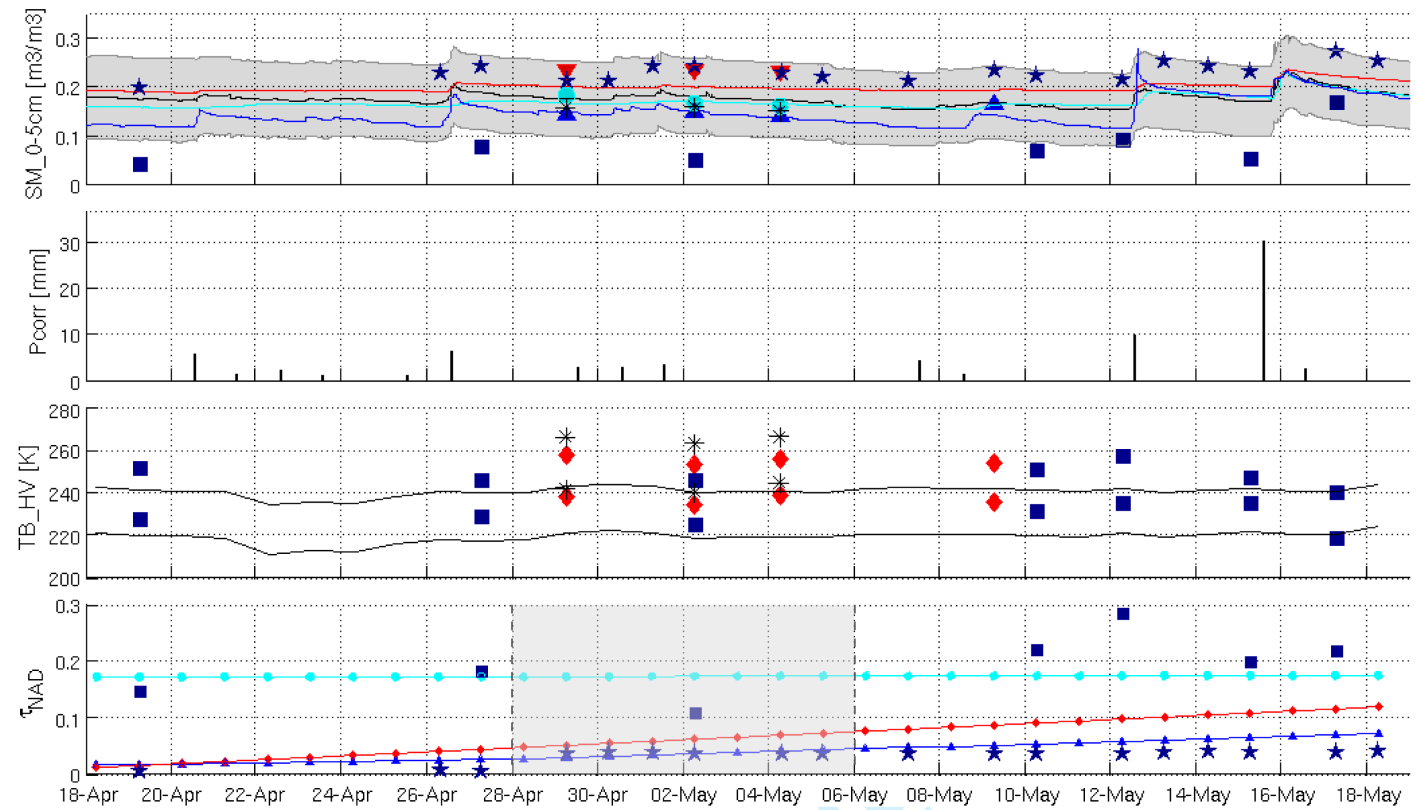

Fig. 6. Surface soil moisture (top panel): 0-5 cm network average and standard deviation (black line and grey-shaded region), 1 network station/campaign sampling patch average in agriculture (medium blue -/triangle), forest (light blue line/circle) and heath (red line/triangle), weighted model patch average over SMOS pixel (black asterix), SMOS L2 initial/filtered retrieved (dark blue star/square); mean of daily precipitation of $10 \mathrm{~km}$ precipitation grid nodes contained within the SMOS pixel (second panel); brightness temperatures, H/V polarization (lower/upper data), at 40 incidence angle (third panel): EMIRAD (red diamond), weighted model patch average (black asterix), model network average (black line), SMOS L1C (dark blue square); $\tau_{N A D}$ (bottom panel): campaign sampling patch average in agriculture (medium blue line/triangle), forest (light blue line/bullet) and heath (red line/triangle) SMOS L2 initial/filtered retrieved (dark blue star/square), period between vegetation sampling dates is marked as grey-shaded region; April 18 - May 18, 2010. 